\title{
Cytokeratin-19 fragments in serum (CYFRA 2I-I) as a marker in primary liver cancer
}

\author{
T Uenishi",', S Kubo', K Hirohashi', H Tanaka', T Shuto', T Yamamoto' and S Nishiguchi' \\ 'Department of Hepato-Biliary-Pancreatic Surgery, Osaka City University Graduate School of Medicine, 1-4-3 Asahimachi, Abeno-ku, Osaka 545-8585, \\ Japan; '2Department of Hepatology, Osaka City University Graduate School of Medicine, 1-4-3 Asahimachi, Abeno-ku, Osaka 545-8585, Japan
}

Using an electrochemiluminescence immunoassay, CYFRA 21 - I concentrations were measured in sera from 187 patients with primary liver cancer ( 64 with hepatocellular carcinoma (HCC) and 23 with intrahepatic cholangiocarcinoma (ICC)) and 87 patients with benign liver diseases. Concentrations of CYFRA 21 - I were significantly higher in patients with ICC (5.0; interquartile range 3. I $10.7 \mathrm{ng} \mathrm{ml}^{-1}$ ) than in those with benign liver disease (I.4; I.0- I.9; Mann-Whitney U-test, $P<0.000$ I) or HCC (I.7; I.I - 2.7; MannWhitney $U$-test, $P<0.000 \mathrm{I})$. Using cutoff values selected for $95 \%$ specificity in the benign group $\left(3.0 \mathrm{ng} \mathrm{ml}^{-1}\right), \mathrm{CYFRA} 2 \mathrm{I}-\mathrm{I}$ showed higher sensitivity for ICC (87.0\%) than three commonly used markers including $\alpha$-fetoprotein (I7.4\%), carcinoembryonic antigen (34.8\%), and carbohydrate antigen 19-9 (60.9\%). Serum CYFRA 2 I-I increased in ICC from stages I/II to IV (Kruskal-Wallis test, $P=0.0102)$. CYFRA 21 - I concentration increased with extent of local invasion, but not nodal status. Serum CYFRA 2 I- I represents a useful diagnostic test for ICC that offers high sensitivity. CYFRA $2 \mathrm{I}$ - I reflected differences in tumour burden, suggesting applicability to staging and follow-up.

British Journal of Cancer (2003) 88, I894- |899. doi:I0.1038/sj.bjc.6601026 www.bjcancer.com

(c) 2003 Cancer Research UK

Keywords: CYFRA 2 I - l; tumour marker; primary liver carcinoma; intrahepatic cholangiocarcinoma

Hepatocellular carcinoma (HCC), one of the most common primary malignant tumours worldwide, is a leading cause of death (Pisani et al, 1999). Since chronic infection with hepatitis B or C virus (HBV or HCV) is closely related to development of HCC (Ikeda et al, 1993; Nishiguchi et al, 1995; Takano et al, 1995), close follow-up of patients with HBV or HCV infection has been recommended to improve early HCC detection and maximise opportunity for successful treatment (Liaw et al, 1986; Curley et al, 1995; Trevisani et al, 2002). While various imaging modalities can be applied to diagnosis of primary liver cancer, the main diagnostic test remains measurement of $\alpha$-fetoprotein (AFP), the best accepted serum tumour marker for HCC, in addition to imaging (Oka et al, 1994; Curley et al, 1995; Trevisani et al, 2002).

Recent studies reported an increased risk of developing intrahepatic cholangiocarcinoma (ICC) in patients with cirrhosis, as is true for HCC (Sorensen et al, 1998; Kobayashi et al, 2000). In Japan and east Asia, chronic HCV infection has been linked to a high incidence of ICC, including combined hepato-cholangiocellular carcinoma (c-HCC-CC) (Tomimatsu et al, 1993; Shin et al, 1996; Su et al, 1996; Taguchi et al, 1996; Yamamoto et al, 1998). Follow-up of patients with HCV infection therefore can detect many cases of ICC as well as HCC. Although serum concentrations of carcinoembryonic antigen (CEA) and carbohydrate antigen (CA) 19-9 are commonly measured to detect and monitor of ICC, insufficient sensitivity and specificity has been a problem with

*Correspondence: Dr T Uenishi;

E-mail:m6877710@msic.med.osaka-cu.ac.jp

Received 3 January 2003; revised 24 March 2003; accepted 26 March 2003 using these established markers in this form of cancer (Kawarada and Mizumoto, 1984, 1990; Wang et al, 1994; Yamanaka et al, 1995; Nakamura et al, 1996; Chu et al, 1997; Kim et al, 1999). A more accurate marker for ICC is needed.

In malignant epithelial cells, activated protease increases degradation of cytokeratin; this results in release of large amounts of cytokeratin fragments into the blood (Dohmoto et al, 2001; Wu et al, 2002). The CYFRA 21-1 assay was developed to measure a soluble fragment of cytokeratin 19 in serum. In non-small-cell lung cancer, CYFRA 21-1 was found to be significantly more sensitive than established markers, and this test may be a useful adjunct in clinical monitoring during and following treatment (Pujol et al, 1993; Stieber et al, 1993; Sugama et al, 1994; van der Gaast et al, 1994; Takada et al, 1995; Lai et al, 1996; Brechot et al, 1997; Nisman et al, 1998). In addition to lung cancer, CYFRA 21-1 has been reported to be a useful marker for cervical carcinoma (Gaarenstroom et al, 1995; Doweck et al, 2000), oesophageal cancer (Brockmann et al, 2000; Kawaguchi et al, 2000), breast cancer (Nakata et al, 2000), gastric cancer (Nakata et al, 1996), and bladder cancer - (Sanchez-Carbayo et al, 1999). Little is known, however, about the clinical significance of serum CYFRA 21-1 in primary liver cancer, although Kashihara et al (1998) have reported marked high concentration of serum CYFRA 21-1 in four patients with severe advanced ICC. As cytokeratin 19 is abundant in ICC (Osborn et al, 1986; Balaton et al, 1988; Johnson et al, 1988; Moll et al, 1992), serum CYFRA 21-1 may be useful for diagnosing and monitoring these neoplasms. In assessing relations to histologic type and pathologic stage in primary liver cancer, we compared serum CYFRA 21-1 with three widely used tumour markers: AFP, CEA, and CA 19-9 in large number of patients with primary liver cancer. 


\section{MATERIALS AND METHODS}

\section{Patients}

The study was performed retrospectively using consecutively obtained samples from 187 patients who underwent hepatic resection for primary liver cancer. Serum samples were collected just before surgery and were stored at $-80^{\circ} \mathrm{C}$ until analysis. All patients were referred to the Department of Hepato-BiliaryPancreatic Surgery at Osaka City University Hospital between 1994 and December 2001, and had histologically confirmed primary liver cancer. Their characteristics are listed in Table 1. The patient population included 164 patients with HCC and 23 with ICC; of the latter, six had c-HCC-CC. Tumour stage was defined according to the pathologic tumour-nodes-metastasis (pTNM) classification proposed by the International Union Against Cancer (Sobin and Wittekind, 1997).

Control blood samples were obtained from 87 patients with nonmalignant liver diseases (Table 1). These patients were diagnosed using clinical, radiologic, and laboratory criteria. Diagnoses of cirrhosis were confirmed by liver biopsy specimen examination. This study was conducted in accordance with the Helsinki Declaration and the guidelines of the Ethics Committee of our institution. Informed consent was obtained from each patient.

\section{Measurement of tumour markers}

We measured CYFRA 21-1 using an electrochemiluminescent immunoassay (ECLIA). The assay, using an Elecsys 2010 analyser (Roche Diagnostics, Basel, Switzerland), is based on the ability of an electrochemically luminescent molecule, a tris(2,2'-bipyridyl)ruthenium (II) complex, to be repeatedly excited by tripropylamine. The system can be applied to both competitive and sandwich-format immunoassays. CYFRA 21-1 was recognised by two mouse monoclonal antibodies, a biotinylated monoclonal cytokeratin 19-specific antibody (Ks 19-1) and a monoclonal cytokeratin 19-specific antibody (BM 19-21), directed against two different epitopes of a fragment of cytokeratin 19. In the first incubation, Ks 19-1 and BM 19-21 labelled with a ruthenium complex were allowed to react, forming a sandwich complex. The next incubation followed addition of streptavidin-coated microparticles, so the sandwich complex could bind to the particulate solid phase via interaction of biotin and streptavidin. The reaction

Table I Characteristics of I 87 patients with primary liver cancer and 87 controls with benign liver disease

\begin{tabular}{lc}
\hline Primary liver cancer & \\
Median age, years (range) & $\mathbf{6 3} \mathbf{( 3 5 - 7 9 )}$ \\
Gender (male: female) & $\mathbf{1 5 I : 3 6}$ \\
Histology & $\mathbf{1 6 4}$ \\
Hepatocellular carcinoma & $\mathbf{2 3}$ \\
Intrahepatic cholangiocarcinoma & \\
Stage & $\mathbf{2 8}$ \\
I & $\mathbf{9 2}$ \\
II & $\mathbf{3 6}$ \\
III & $\mathbf{3 1}$ \\
IV & \\
Benign liver disease & $\mathbf{6 0} \mathbf{( 2 2 - 7 6 )}$ \\
Median age, years (range) & $\mathbf{6 4 : 2 3}$ \\
Gender (male: female) & \\
Histology & $\mathbf{6 3}$ \\
Chronic hepatitis C & $\mathbf{6}$ \\
Chronic hepatitis B & $\mathbf{1 6}$ \\
Liver cirrhosis & $\mathbf{2}$ \\
Haemangioma & \\
\hline
\end{tabular}

mixture then was aspirated into the measuring cell, where the microparticles were captured magnetically upon the surface of the electrode. Unbound reactants were removed with a phosphatetripropylamine buffer. Application of voltage to the electrode then induced chemiluminescent emission that was measured by a photomultiplier.

For comparison, conventional tumour markers (CEA, CA 19-9, and AFP) were measured by a chemiluminescent immunoassay (CLIA).

\section{Statistical analysis}

Data are given as the median with 25th and 75th percentiles of marker concentrations. Kruskal-Wallis one-way analysis of variance was performed initially for multiple-comparison tests. When this analysis was significant, pairs of groups were compared using the Mann-Whitney $U$-test. To compare abilities of tumour markers to distinguish patients with primary liver cancers from those with benign liver disease, receiver operator characteristic (ROC) curves, which correlate true- and false-positive rates (sensitivity and (1-specificity)), were constructed using the ROCKIT program (Metz et al, 1998a, b). In addition, areas under the ROC curve (AUC) were calculated for each marker. The statistical significance of differences between the two AUCs also was determined.

\section{RESULTS}

\section{CYFRA 21-1 distribution and histologic type of primary liver cancer}

Significant differences in CYFRA 21-1 concentration (median and interquartile range) were noted between patients with primary liver cancer (1.9; interquartile range $1.1-3.1 \mathrm{ng} \mathrm{ml}^{-1}$ ) and those with benign liver disease $(1.4 ; 1.0-1.9$; Mann-Whitney $U$-test, $P=0.0009)$. Distributions of serum CYFRA 21-1 concentrations for HCC (1.7; 1.1-2.7), ICC (5.0; 3.1-10.7), and benign liver disease are shown in Figure 1. Significantly higher concentrations of CYFRA 21-1 were noted in patients with ICC than in those with benign liver disease (Mann-Whitney $U$-test, $P<0.0001)$ or HCC $(P<0.0001)$. 


\section{Sensitivities of CYFRA 21-1 and other tumour markers}

Table 2 shows the results for serum concentration and sensitivity of AFP, CEA, CA 19-9, and CYFRA 21-1 in relation to histological type. When cutoff values were selected according to $95 \%$ specificity in the benign group, the cutoff values were $20.3 \mathrm{ng} \mathrm{ml}^{-1}$ for AFP, $4.8 \mathrm{ng} \mathrm{ml}^{-1}$ for CEA, $47.0 \mathrm{U} \mathrm{ml}^{-1}$ for CA 19-9, and $3.0 \mathrm{ng} \mathrm{ml}^{-1}$ for CYFRA 21-1. AFP demonstrated a higher sensitivity (59.1\%) than other markers in patients with HCC. In patients with ICC, the most sensitive marker was CYFRA 21-1 (87.0\%). Although CA 19-9 showed relatively high sensitivity in ICC patients $(60.9 \%)$, the sensitivity of CA $19-9$ was $33.5 \%$ in HCC patients.

\section{Analysis of ROC curves}

Receiver operator characteristic curves were constructed to compare the ability of the four markers to differentiate between patients with malignant and benign liver disease. Curves for HCC (Figure 2) and ICC (Figure 3) in distinction to benign liver disease are illustrated. For patients with HCC, the AUC was $0.81 \pm 0.03$, $0.61 \pm 0.04,0.64 \pm 0.03$, and $0.58 \pm 0.04$ for AFP, CEA, CA 19-9, and CYFRA 21-1, respectively. The AUC for AFP differed significantly from that for other markers $(P<0.0001)$. For patients with ICC, the AUC was $0.53 \pm 0.08,0.81 \pm 0.05,0.86 \pm 0.06$, and $0.95 \pm 0.03$ for AFP, CEA, CA 19-9, and CYFRA 21-1, respectively. A significant difference was noted between the AUC for CYFRA 21-1 and those for CEA $(P=0.0196)$ and AFP $(P<0.0001)$; on the other hand, no significant difference was noted between the AUC for CYFRA 21-1 and that for CA 19-9 $(P=0.0913)$. In the ICC group, ROC analysis demonstrated that CYFRA 21-1 was superior to the other markers.

\section{CYFRA 21-1 and pathologic variables in patients with ICC}

For 23 patients with ICC, CYFRA 21-1 concentrations were compared according to disease stage (Table 3, Figure 4). Median and interquartile range of serum CYFRA 21-1 concentrations were $3.2(3.1-3.8), 4.4(3.1-7.6)$, and $11.5(7.8-12.2)$ for stages I/II, III, and IV, respectively. An overall tendency towards an increase in serum concentration was observed from stages I/II to IV, and a significant difference was noted (Kruskal-Wallis test, $P=0.0102$ ). No significant difference was evident for serum CEA or CA 19-9 concentration between tumour stages (Kruskal-Wallis test; $P=0.0774$ and 0.1252 , respectively). The serum CYFRA 21-1 concentration also differed significantly according to the $\mathrm{T}$ factor by the TNM classification (Table 3, Figure 4). Median and interquartile ranges of serum CYFRA 21-1 concentrations were $3.1(2.1-3.7), 4.4(3.2-6.4)$, and $11.5(7.8-12.2)$ for $\mathrm{T} 1 / 2$, T3, and T4, respectively (Kruskal-Wallis test, $P=0.0038$ ). Tumour size and vascular invasion were related to serum CYFRA 21-1 concentration, while serum CYFRA 21-1 concentration did not differ according to nodal status.

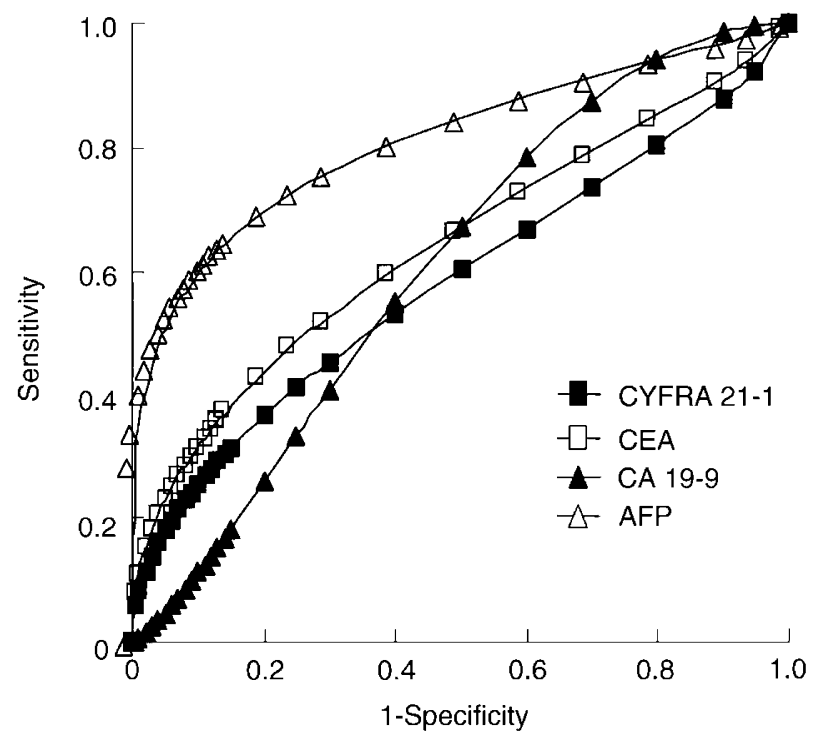

Figure 2 Receiver operating characteristic (ROC) curves in patients with hepatocellular carcinoma and benign liver disease were constructed.

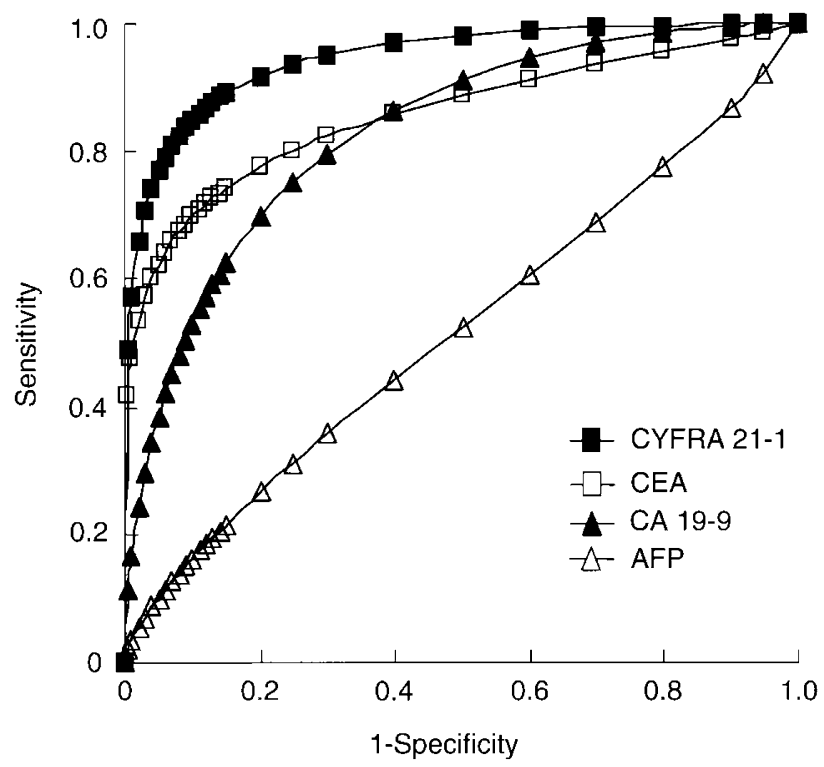

Figure 3 Receiver operating characteristic (ROC) curves in patients with intrahepatic cholangiocarcinoma and benign liver disease were constructed.

Table 2 Sensitivity of tumour markers in patients with primary liver cancer

\begin{tabular}{|c|c|c|c|c|}
\hline & CEA $\left(\mathrm{ng} \mathrm{ml}^{-1}\right)$ & CA $19.9\left(\mathrm{U} \mathrm{ml}^{-1}\right)$ & $\operatorname{AFP}\left(\mathrm{ng} \mathrm{ml}^{-1}\right)$ & CYFRA2I-I (ng ml $\left.{ }^{-1}\right)$ \\
\hline Median & $1.8(1.3-2.7)$ & $16.0(7.0-25.8)$ & $6.5(3.7-11.0)$ & $1.4(1.0-1.9)$ \\
\hline Cutoff value & 4.8 & 47.0 & 20.3 & 3.0 \\
\hline Median & $2.8(1.6-3.2)$ & $23.0(12.0-44.0)$ & $38.5(8.1-328.3)$ & $1.7(1.1-2.7)$ \\
\hline Sensitivity & $5.5 \%(9 / 164)$ & $33.5 \%(55 / 164)$ & $59.1 \%(97 / 164)$ & $17.1 \%(28 / 164)$ \\
\hline \multicolumn{5}{|l|}{ ICC } \\
\hline
\end{tabular}

Data are given as the median with 25th and 75th percentiles of marker concentrations. Cutoff values selected according to $95 \%$ specificity in the benign group. $\mathrm{CEA}=$ carcinoembryonic antigen; fetoprotein $=$ AFP. 
Table 3 Serum CYFRA 2I-I concentrations of 23 patients with intrahepatic cholangiocarcinoma

\begin{tabular}{|c|c|c|c|}
\hline & Number & Median (interquartile range) & $P$-value \\
\hline \multicolumn{4}{|c|}{ Tumour size $(\mathrm{cm})$} \\
\hline$\leqslant 4.0$ & 12 & $3.2(2.7-4.4)$ & \multirow[t]{2}{*}{$0.0068^{\mathrm{a}}$} \\
\hline$>4.0$ & 11 & $9.3(5.0-11.6)$ & \\
\hline \multicolumn{4}{|c|}{ Vascular invasion } \\
\hline Present & 13 & $8.4(4.0-11.9)$ & \multirow[t]{2}{*}{$0.0218^{a}$} \\
\hline Absent & 10 & $2.7(3.1-5.1)$ & \\
\hline \multicolumn{4}{|c|}{ Number of tumour } \\
\hline Single & 12 & $3.6(3.1-5.1)$ & \multirow[t]{2}{*}{$0.0648^{\mathrm{a}}$} \\
\hline Multiple & 11 & $7.6(3.5-12.0)$ & \\
\hline \multicolumn{4}{|l|}{$T$ factor } \\
\hline $\mathrm{TI} / 2$ & 7 & $3.1(2.1-3.7)$ & \multirow{3}{*}{$0.0038^{b}$} \\
\hline T3 & 9 & $4.4(3.2-6.4)$ & \\
\hline T4 & 7 & $11.5(7.8-12.2)$ & \\
\hline \multicolumn{4}{|c|}{ Lymph node metastasis } \\
\hline Present & 6 & $6.9(3.4-12.1)$ & \multirow[t]{2}{*}{$0.3627^{\mathrm{a}}$} \\
\hline Absent & 17 & $4.2(3.1-9.6)$ & \\
\hline \multicolumn{4}{|l|}{ Stage } \\
\hline$|/| \mid$ & 6 & $3.2(3.1-3.8)$ & \multirow[t]{3}{*}{$0.0102^{b}$} \\
\hline III & 10 & $4.4(3.1-7.6)$ & \\
\hline IV & 7 & $11.5(7.8-12.2)$ & \\
\hline
\end{tabular}

aMann-Whitney U-test, ${ }^{\text {b }}$ ruskal-Wallis test.

\section{DISCUSSION}

ICC, including c-HCC-CC, has been reported to carry a poorer postoperative prognosis than HCC reflecting more aggressive invasion and frequent metastasis, especially to lymph nodes (Maeda et al, 1995; Madariaga et al, 1998; Uenishi et al, 2000; Inoue et al, 2000; Uenishi et al, 2001). Early diagnosis and curative surgical resection therefore provide the only chance of long-term survival for patients with ICC. Despite advances and refinements, no tumour marker has shown satisfactory sensitivity or specificity for early detection of ICC, for estimating extent of disease, or for monitoring response to treatment. Thus, a reliable marker for ICC would be a valuable addition to available diagnostic tests. Cytokeratins are cytoskeletal intermediate filaments present in almost all normal and malignant epithelial cells (Moll et al, 1992). Characteristic combinations of cytokeratin polypeptides are expressed in different epithelia depending on the organ and/or type of differentiation (Osborn et al, 1986; Moll et al, 1992). Epithelial cells in the liver also express characteristic cytokeratins. In normal human liver, hepatocytes express cytokeratins 8 and 18, while bile duct cells also contain cytokeratins 7 and 19 (Osborn et al, 1986; Balaton et al, 1988; Johnson et al, 1988; Moll et al, 1992). Since this cytokeratin pattern ordinarily is preserved during neoplastic transformation, ICC and the CC component of c-HCCCC contain cytokeratin 19, while HCC does not (Osborn et al, 1986; Balaton et al, 1988; Johnson et al, 1988; Moll et al, 1992). Therefore, a soluble fragment of cytokeratin 19, CYFRA 21-1, may be a useful marker for ICC. Kashihara et al (1998) have reported that high serum concentrations of CYFRA 21-1 in patients with large liver cancer would suggest the existence of ICC rather than HCC, since serum concentration of CYFRA 21-1 markedly elevated in four patients with ICC, compared with that in 13 patients with HCC. However, all the four patients had severe advanced and unresectable tumours. We evaluated serum CYFRA 21-1 concentrations in 23 patients with various stage ICC to determine the usefulness of CYFRA 21-1 as a marker for diagnosis of ICC, and also to identify relation between CYFRA 21-1 levels and various histological features including components of tumour staging schema.

Tumour markers such as CA 19-9 and CEA can be used in combination not only for diagnosis of gastrointestinal malignancies but also for monitoring during and in follow-up treatment. Some investigators have recommended that a possible diagnosis of ICC should be considered when a hepatic tumour is associated with high-serum CEA concentration, since serum CEA had relatively high sensitivity in patients with ICC (Kawarada and Mizumoto, 1984; Wang et al, 1994). Kubo et al (1995) reported that a high-serum CEA concentration strongly suggests ICC in patients with hepatolithiasis, even when no hepatic tumour is detected. Generally, however, serum CEA concentrations are elevated in only $20-45 \%$ of patients with ICC (Yamanaka et al, 1995; Chu et al, 1997; Harrison et al, 1998; Kashihara et al, 1998; Kim et al, 1999; Uenishi et al, 2001). In the present study, serum CEA also showed a low sensitivity for ICC (34.8\%). While serum CEA may be helpful in diagnosis of some ICC and in follow-up of patients who showed elevated titres prior to surgery, it is not sufficiently sensitive or specific for reliable diagnosis of the disease (Kawarada and Muzumoto, 1984; Wang et al, 1994). CA 19-9 currently is in wide use, particularly for detecting bile duct cancer in patients with primary sclerosing cholangitis (PSC) (Nichols et al, 1993; Ramage et al, 1995; Bergquist et al, 1998; Chalasani et al, 2000). Serum CA 19-9 concentrations also are elevated in $65-80 \%$ of patients with ICC, and CA 19-9 has been considered the most sensitive serologic marker for diagnosis and follow-up of ICC (Kawarada and Mizumoto, 1990; Yamanaka et al, 1995; Kim et al, 1999; Uenishi et al, 2001). However, when we used a cutoff value giving a specificity of $95 \%$ vs benign liver disease, CYFRA 21-1 had the highest diagnostic sensitivity for ICC (87.0\%). Importantly,
Figure 4 Distribution of individual serum CYFRA 2I- I values according to stage (upper) and $\mathrm{T}$ factor (lower) in patients with intrahepatic cholangiocarcinoma. 
sensitivity of serum CYFRA 21-1 for HCC was low in this study (17.1\%). Although the sensitivity of CA $19-9$ was relatively high in our patients with ICC $(60.9 \%)$, its specificity for ICC was limited; serum CA $19-9$ was elevated in $33.5 \%$ of HCC patients. Serum CYFRA 21-1 therefore may be a particularly useful marker for distinguishing ICC from HCC in a radiologically demonstrated hepatic tumour. However, our study could not clarify whether screening for serum CYFRA 21-1 detects very early ICC, since only two patients had a stage I tumour. Apparent sensitivity of a tumour marker in a study is influenced by several factors, particularly numbers of patients in early or advanced stages of cancer. Some investigators have indicated that serum CYFRA 21-1 may be useful for early detection of non-small-cell lung cancer, where CYFRA 211 elevations were common even in patients with early stage disease (Sugama et al, 1994; Takada et al, 1995). Prospective studies are needed to assess the place of CYFRA 21-1 in screening for ICC.

When two or more tests are available for use in diagnosis, comparison of ROC curves often will indicate which is best. The diagnostic test with the ROC curve enclosing the largest area is most accurate. For example, a high degree of specificity and sensitivity of CYFRA 21-1 for diagnosis of non-small cell lung cancer was shown by ROC curve findings (Pujol et al, 1993; Stieber et al, 1993; Sugama et al, 1994; Takada et al, 1995; Nisman et al, 1998). Analysis of the AUCs clearly showed better discrimination

\section{REFERENCES}

Balaton AJ, Nehama-Sibony M, Gotheil C, Callard P, Baviera EE (1988) Distinction between hepatocellular carcinoma, cholangiocarcinoma, and metastatic carcinoma based on immunohistochemical staining for carcinoembryonic antigen and for cytokeratin 19 on paraffin sections. J Pathol 156: 305-310

Bergquist A, Glaumann H, Persson B, Broome U (1998) Risk factors and clinical presentation of hepatobiliary carcinoma in patients with primary sclerosing cholangitis: a case-control study. Hepatology 27: 311-316

Brechot JM, Chevret S, Nataf J, Le Gall C, Fretault J, Rochemaure J, Chastang C (1997) Diagnostic and prognostic value of Cyfra 21-1 compared with other tumour markers in patients with non-small cell lung cancer: a prospective study of 116 patients. Eur J Cancer 33: $385-391$

Brockmann JG, St Nottberg H, Glodny B, Heinecke A, Senninger NJ (2000) CYFRA 21-1 serum analysis in patients with esophageal cancer. Clin Cancer Res 6: 4249-4252

Chalasani N, Baluyut A, Ismail A, Zaman A, Sood G, Ghalib R, McCashland TM, Reddy KR, Zervos X, Anbari MA, Hoen H (2000) Cholangiocarcinoma in patients with primary sclerosing cholangitis: a multicenter case - control study. Hepatology 31: 7-11

Chu KM, Lai EC, Al-Hadeedi S, Arcilla Jr CE, Lo CM, Liu CL, Fan ST, Wong J (1997) Intrahepatic cholangiocarcinoma. World J Surg 21: 301-306

Curley SA, Izzo F, Gallipoli A, De Bellis M, Cremona F, Parisi V (1995) Identification and screening of 416 patients with chronic hepatitis at high risk to develop hepatocellular cancer. Ann Surg 222: 375-383

Dohmoto K, Hojo S, Fujita J, Yang Y, Ueda Y, Bandoh S, Yamaji Y, Ohtsuki Y, Dobashi N, Ishida T, Takahara J (2001) The role of caspase 3 in producing cytokeratin 19 fragment (CYFRA21-1) in human lung cancer cell lines. Int J Cancer 91: 468-473

Doweck I, Barak M, Uri N, Greenberg E (2000) The prognostic value of the tumour marker Cyfra 21-1 in carcinoma of head and neck and its role in early detection of recurrent disease. Br J Cancer 83: 1696-1701

Gaarenstroom KN, Bonfrer JM, Kenter GG, Korse CM, Hart AA, Trimbos JB, Helmerhorst TJ (1995) Clinical value of pretreatment serum Cyfra 211 , tissue polypeptide antigen, and squamous cell carcinoma antigen levels in patients with cervical cancer. Cancer 76: 807-813

Harrison LE, Fong Y, Klimstra DS, Zee SY, Blumgart LH (1998) Surgical treatment of 32 patients with peripheral intrahepatic cholangiocarcinoma. Br J Surg 85: $1068-1070$

Ikeda K, Saitoh S, Koida I, Arase Y, Tsubota A, Chayama K, Kumada H, Kawanishi M (1993) A multivariate analysis of risk factors for hepatocellular carcinogenesis: a prospective observation of 795 patients with viral and alcoholic cirrhosis. Hepatology 18: 147-153 between ICC and benign liver diseases for CYFRA 21-1 than for CEA or CA 19-9. These results indicated that serum CYFRA 21-1 should be a useful and reliable tumour marker for ICC.

Previous studies have validated CYFRA 21-1 as a marker for monitoring disease in patients with various cancers, especially since CYFRA 21-1 concentrations and the sensitivity of CYFRA 211 increased progressively with clinical stage (Pujol et al, 1993; Sugama et al, 1994; Gaarenstroom et al, 1995; Takada et al, 1995; van der Gaast et al, 1995; Lai et al, 1996; Nakata et al, 1996; Brechot et al, 1997; Nisman et al, 1998; Brockmann et al, 2000; Doweck et al, 2000; Kawaguchi et al, 2000; Nakata et al, 2000) Our study also demonstrated that serum CYFRA 21-1 concentration was related to tumour stage of ICC, while serum CEA and CA 19-9 concentrations were not. CYFRA 21-1 concentrations differed according to the tumour size and vascular invasion, but not according to the number of tumours or nodal status. These results suggested that CYFRA 21-1 should be useful for disease staging and monitoring in patients with ICC.

In conclusion, serum CYFRA 21-1 should be a useful diagnostic test for ICC given its outstanding sensitivity. Serum CYFRA 21-1 concentrations reflected differences in ICC tumour burden, so this marker also could be applied to staging and monitoring. Prospective studies should be performed to evaluate the real impact of serum CYFRA 21-1 as a marker for ICC.
Inoue $\mathrm{K}$, Makuuchi M, Takayama T, Torzilli G, Yamamoto J, Shimada K, Kosuge T, Yamasaki S, Konishi M, Kinoshita T, Miyagawa S, Kawasaki S (2000) Long-term survival and prognostic factors in the surgical treatment of mass-forming type cholangiocarcinoma. Surgery 127: $498-505$

Johnson DE, Herndier BG, Medeiros LJ, Warnke RA, Rouse RV (1988) The diagnostic utility of the keratin profiles of hepatocellular carcinoma and cholangiocarcinoma. Am J Surg Pathol 12: 187-197

Kashihara T, Ohki A, Kobayashi T, Sato T, Nishizawa H, Ogawa K, Tako H, Kawakami F, Tsuji M, Tamaoka K (1998) Intrahepatic cholangiocarcinoma with increased serum CYFRA 21-1 level. J Gastroenterol 33: $447-453$

Kawaguchi H, Ohno S, Miyazaki M, Hashimoto K, Egashira A, Saeki H, Watanabe M, Sugimachi K (2000) CYFRA 21-1 determination in patients with esophageal squamous cell carcinoma: clinical utility for detection of recurrences. Cancer 89: 1413-1417

Kawarada Y, Mizumoto R (1984) Cholangiocellular carcinoma of the liver. Am J Surg 147: $354-359$

Kawarada Y, Mizumoto R (1990) Diagnosis and treatment of cholangiocellular carcinoma of the liver. Hepatogastroenterology 37: $176-181$

Kim HJ, Yun SS, Jung KH, Kwun WH, Choi JH (1999) Intrahepatic cholangiocarcinoma in Korea. J Hep Bil Pancr Surg 6: 142-148

Kobayashi M, Ikeda K, Saitoh S, Suzuki F, Tsubota A, Suzuki Y, Arase Y, Murashima N, Chayama K, Kumada H (2000) Incidence of primary cholangiocellular carcinoma of the liver in Japanese patients with hepatitis C virus-related cirrhosis. Cancer 88: 2471-2477

Kubo S, Kinoshita H, Hirohashi K, Hamba H (1995) Hepatolithiasis associated with cholangiocarcinoma. World J Surg 19: 637-641

Lai RS, Hsu HK, Lu JY, Ger LP, Lai NS (1996) CYFRA 21-1 enzyme-linked immunosorbent assay: evaluation as a tumor marker in non-small cell lung cancer. Chest 109: $995-1000$

Liaw YF, Tai DI, Chu CM, Lin DY, Sheen IS, Chen TJ, Pao CC (1986) Early detection of hepatocellular carcinoma in patients with chronic type B hepatitis: a prospective study. Gastroenterology 90: $263-267$

Madariaga JR, Iwatsuki S, Todo S, Lee RG, Irish W, Starzl TE (1998) Liver resection for hilar and peripheral cholangiocarcinoma: a study of 62 cases. Ann Surg 227: $70-79$

Maeda T, Adachi E, Kajiyama K, Sugimachi K, Tsuneyoshi M (1995) Combined hepatocellular and cholangiocarcinoma: proposed criteria according to cytokeratin expression and analysis of clinicopathologic features. Hum Pathol 26: 956-964 
Metz CE, Herman BA, Roe CA (1998a) Statistical comparison of two ROCcurve estimates obtained from partially-paired datasets. Med Decis Making 18: $110-121$

Metz CE, Herman BA, Shen JH (1998b) Maximum likelihood estimation of receiver operating characteristic (ROC) curves from continuouslydistributed data. Stat Med 17: $1033-1053$

Moll R, Franke WW, Schiller DL, Geiger B, Krepler R (1992) The catalog of human cytokeratins: patterns of expression in normal epithelia, tumors and cultured cells. Cell 31: $11-24$

Nakamura S, Suzuki S, Sakaguchi T, Serizawa A, Konno H, Baba S, Muro H (1996) Surgical treatment of patients with mixed hepatocellular carcinoma and cholangiocarcinoma. Cancer 78: 1671-1676

Nakata B, Chung Ys, Kato Y, Ogawa M, Ogawa Y, Inui A, Maeda K, Sawada T, Sowa M (1996) Clinical significance of serum CYFRA 21-1 in gastric cancer. Br J Cancer 73: $1529-1532$

Nakata B, Ogawa Y, Ishikawa T, Ikeda K, Kato Y, Nishino H, Hirakawa K (2000) Serum CYFRA 21-1 is one of the most reliable tumor markers for breast carcinoma. Cancer 89: 1285-1290

Nichols JC, Gores GJ, Larusso NF, Wiesner RH, Nagorney DM, Ritts Jr RE (1993) Diagnostic role of serum CA 19-9 for cholangiocarcinoma in patients with primary sclerosing cholangitis. Mayo Clin Proc 68: $874-879$

Nishiguchi S, Kuroki T, Nakatani S, Morimoto H, Takeda T, Nakajima S, Shiomi S, Seki S, Kobayashi K, Otani S (1995) Randomised trial of effects of interferon-alpha on incidence of hepatocellular carcinoma in chronic active hepatitis C with cirrhosis. Lancet 346: 1051 - 1055

Nisman B, Lafair J, Heching N, Lyass O, Baras M, Pretz T, Barak V (1998) Evaluation of tissue polypeptide specific antigen, CYFRA 21-1, and carcinoembryonic antigen in nonsmall cell lung carcinoma: does the combined use of cytokeratin markers give any additional information? Cancer 82: $1850-1859$

Oka H, Tamori A, Kuroki T, Kobayashi K, Yamamoto S (1994) Prospective study of alpha-fetoprotein in cirrhotic patients monitored for development of hepatocellular carcinoma. Hepatology 19: 61-66

Osborn M, Van Lessen G, Weber K, Kloppel G, Altmannsberger M (1986) Different diagnosis of gastrointestinal carcinoma by using monoclonal antibodies specific for individual keratin polypeptides. Lab Invest 55: $497-504$

Pisani P, Parkin DM, Bray F, Ferlay J (1999) Estimates of the worldwide mortality from 25 cancers in 1990. Int J Cancer 83: 18-29

Pujol JL, Grenier J, Daures JP, Daver A, Pujol H, Michel FB (1993) Serum fragment of cytokeratin subunit 19 measured by CYFRA 21-1 immunoradiometric assay as a marker of lung cancer. Cancer Res 53: $61-66$

Ramage JK, Donaghy A, Farrant JM, Iorns R, Williams R (1995) Serum tumor markers for the diagnosis of cholangiocarcinoma in primary sclerosing cholangitis. Gastroenterology 108: 865-869

Sanchez-Carbayo M, Espasa A, Chinchilla V, Herrero E, Megias J, Mira A, Soria F (1999) New electrochemiluminescent immunoassay for the determination of CYFRA 21-1: analytical evaluation and clinical diagnostic performance in urine samples of patients with bladder cancer. Clin Chem 45: $1944-1953$

Shin HR, Lee CU, Park HJ, Seol SY, Chung JM, Choi HC, Ahn YO, Shigematsu T (1996) Hepatitis B and C virus, Clonorchis sinensis for the risk of liver cancer: a case - control study in Pusan, Korea. Int J Epidemiol 25: $933-940$
Sobin LH, Wittekind CH (1997) TNM Classification of Malignant Tumours, 5 th edn. New York: Wiley-Liss

Sorensen HT, Friis S, Olsen JH, Thulstrup AM, Mellemkjaer L, Linet M, Trichopoulos D, Vilstrup H, Olsen J (1998) Risk of liver and other types of cancer in patients with cirrhosis: a nationwide cohort study in Denmark. Hepatology 28: 921 - 925

Stieber P, Hasholzner U, Bodenmuller H, Nagel D, Sunder-Plassmann L, Dienemann H, Meier W, Fateh-Moghadam A (1993) CYFRA 21-1: a new marker in lung cancer. Cancer 72: 707-713

Su WC, Chan KK, Lin XZ, Lin PW, Chow NH, Shin JS, Chen CY, Tsao CJ (1996) A clinical study of 130 patients with biliary tract cancers and periampullary tumors. Oncology 53: 488-493

Sugama Y, Kitamura S, Kawai T, Ohkubo A, Hasegawa S, Kuriyama T, Kato H, Fukuoka M, Ohkawa J (1994) Clinical usefulness of CYFRA assay in diagnosing lung cancer: measurement of serum cytokeratin fragment. Jpn J Cancer Res 85: $1178-1184$

Taguchi J, Nakashima O, Tanaka M, Hisaka T, Takazawa T, Kojiro M (1996) A clinicopathological study on combined hepatocellular and cholangiocarcinoma. J Gastroenterol Hepatol 11: 758-764

Takada M, Masuda N, Matsuura E, Kusunoki Y, Matui K, Nakagawa K, Yana T, Tuyuguchi I, Oohata I, Fukuoka M (1995) Measurement of cytokeratin 19 fragments as a marker of lung cancer by CYFRA 21-1 enzyme immunoassay. Br J Cancer 71: $160-165$

Takano S, Yokosuka O, Imazeki F, Tagawa M, Omata M (1995) Incidence of hepatocellular carcinoma in chronic hepatitis $\mathrm{B}$ and $\mathrm{C}$ : a prospective study of 251 patients. Hepatology 21: $650-655$

Tomimatsu M, Ishiguro N, Taniai M, Okuda H, Saito A, Obata H, Yamamoto M, Takasaki K, Nakano M (1993) Hepatitis C virus antibody in patients with primary liver cancer (hepatocellular carcinoma, cholangiocarcinoma, and combined hepatocellular-cholangiocarcinoma) in Japan. Cancer 72: 683-688

Trevisani F, De NS, Rapaccini G, Farinati F, Benvegnu L, Zoli M, Grazi GL, Del PP, Di N, Bernardi M (2002) Semiannual and annual surveillance of cirrhotic patients for hepatocellular carcinoma: effects on cancer stage and patient survival (Italian experience). Am J Gastroenterol 97: 734-744

Uenishi T, Hirohashi K, Kubo S, Yamamoto T, Yamazaki O, Kinoshita H (2001) Clinicopathologic factors predicting outcome after resection of mass-forming intrahepatic cholangiocarcinoma. Br J Surg 88: 969 -974

Uenishi T, Hirohashi K, Shuto T, Yamamoto T, Kubo S, Tanaka H, Ikebe T, Kinoshita H (2000) Surgery for mixed hepatocellular and cholangiocellular carcinoma. Hepatogastroenterology 47: 832-834

van der Gaast A, Schoenmakers CH, Kok TC, Bligenberg BG, Cornilie F, Splinter TA (1994) Evaluation of a new tumour marker in patients with non-small-cell lung cancer: Cyfra 21.1. Br J Cancer 69: 525-528

Wang YJ, Lee SD, Shyu JK, Lo KJ (1994) Clinical experience in 126 patients with tissue-proved proximal cholangiocarcinoma. J Gastroenterol Hepatol 9: 134-137

Wu F, Fujita J, Murota M, Li JQ, Ishida T, Nishioka M, Imaida Y, Kuriyama $S$ (2002) CYFRA 21-1 is released in TNF-alpha-induced apoptosis in the hepatocellular carcinoma cell line HuH-7. Int J Oncol 21: $441-445$

Yamamoto M, Takasaki K, Nakano M, Saito A (1998) Minute nodular intrahepatic cholangiocarcinoma. Cancer 82: 2145-2149

Yamanaka N, Okamoto E, OT, Oriyama T, Fujimoto J, Furukawa K, Tanaka T, Tanaka W, Nishigami T (1995) Clinicopathologic spectrum of resected extraductal mass-forming intrahepatic cholangiocarcinoma. Cancer 76: $2449-2456$ 